\title{
Article \\ Public Perception of Climate Risk: The Case of Greece
}

\author{
Asimina Voskaki ${ }^{1, *}$ and Konstantinos Tsermenidis ${ }^{2}$ \\ 1 Environmental Consultant at Avenvi consulting, Athens, Greece \\ 2 University of Macedonia, Thessaloniki 540 06, Greece; tsermeni@uom.edu.gr \\ * Correspondence: info@avenviconsulting.eu or voskaki@gmail.com; Tel.: +30-697-402-2877
}

\begin{abstract}
Even though Greece is considered a vulnerable region in terms of climate hazards, public perception and attitude do not always identify climate change as an important environmental area of concern, especially when compared to socio-economic issues. The key issue of this paper is to investigate and analyse public perception in Greece as regards to climate change risk. Through a questionnaire survey this paper analyses trends that exist, peoples' opinion and awareness with regards to climate risk and how willing they are to change current lifestyle, to pay or to act to minimize or to prevent the risk. Conventional wisdom of this paper is to highlight factors that influence individual perception and point out drivers of behavior change that can support efficiently future adaptation plans.
\end{abstract}

Keywords: climate risk; climate change; public perception

\section{Introduction}

Climate change is commonly considered as one of the greatest challenges our world is facing [1,2] impacting health, social wellbeing, infrastructures, built environment, and economic development [3-5]. Extreme weather events, associated with climate change, like heavy rainfall and associated flooding, storms, hurricanes, high temperature, heat waves, lack of precipitation and draughts result in hazards that frequently happen over the past years $[4,6]$. These hazards are expected to take place more often in many parts of Europe, affecting European regions in different ways as regards the magnitude and timescale of impact [6,7].

Climate hazards that occurred during the past decades in Europe, like flooding, draughts, wind storms and heat waves were responsible for the death and injuries of many people and for significant economic losses [6]. Based on existing research these extreme weather events will become more frequent in the future and many vulnerable areas will have to face more intense hazards [7].

The impact of climate change in Greece climatic change seems to be associated with sea level rise, increase in temperature, increase in draught periods, variation in precipitation, and extreme weather events [8]. The Mediterranean region, including Greece, is considered to be at high risk as regards climate related hazards, due to low response capacity [7]. Those hazards are expected to impact many sectors of the economy, like agriculture, tourism, transportation, build environment, coastal systems, water infrastructure and resources and result in significant economic losses if proper measures are not implemented [8]. This implies that Greece is in a very difficult position as efforts towards reducing vulnerability and increasing climate resilience are necessary in a period that is trying to overcome economic crisis. This could become even more difficult in cases where there is lack of knowledge and information on the risk and where public perception is influenced by several parameters [9-13].

Up to date research on climate change is focused on analysing economic, social and environmental impact [3,4], addressing vulnerability and assessing potential hazards [14-17] or proposing adaptation options [5]. In addition, there is some literature addressing individual responses to climate change impact and the risk associated with it [18-27,11-12]. 
Understanding peoples' beliefs and how they perceive the climate risk seems to be significant in planning for the future and in implementing adaptation policies. Bellamy and Hulme [19] explored public perception and concluded that climate change is generally perceived as a sudden state by a significant proportion of people and that this perception along with the level of danger that is associated with it mostly depends on respondents' values and beliefs. In general, risk perception analysis is considered important in decision making processes especially those associated with hazardous activities and makes possible the effective communication of policies and risk information [27]. However in many cases public perception is generally ignored in planning processes [26].

Taking into consideration the reviewed literature risk perception can be seen as the understanding one has based on the comprehension of the threat that could result in loss of life or property [26]. Other researchers [28] associate the term public perception with certain risk characteristics and their level like awareness, preparedness and worry. In another research work [23] it is mentioned that individual behavior could be dependent on people's anxiety and insecurity rather than various financial considerations related to mitigation measures.

European Commission [29] suggests that in order to mitigate or adapt to climate change we need to understand individual's attitude and behavior. In particular, in a report published in 2014 it is mentioned that perceptions of climate change significance and willingness to act could also be taken into consideration [29]. Furthermore, a survey that was conducted in 2013 shown that Europeans consider climate change as one of the most serious problems. Four out of five people consider that energy efficiency could be implemented as a measure to mitigate impact but also to boost the economy; however the majority thinks that the responsibility to tackle climate change lies with National Governments [29].

A lot of researchers associate public perception and adaptation policies. The research implemented by Wei et al. [30] suggests that significant gaps exist between perception and action and therefore efforts should be focused to raise awareness in order to address climate change and implement adaptation strategies efficiently. Wolf [31] points out that significant difficulty towards adaptation can be generated from the views of the general public and therefore their perception and understanding could be the key to effective adaptation strategies. Also, Palutikof et al. [18] link efficient adaptation with understanding of peoples' attitudes. De Jalo et al. [32], suggest that understanding public perception and having knowledge of socio-demographic characteristics could result in the development of effective adaptation policies. This is further supported by the work of Niles et al. [33].

Furthermore, socio-demographic characteristics, as well as factors associated with the location seem to be important in shaping the way people perceive risk. The research implemented by Leiserowitz [12] illustrates that risk perception and policy support are influenced by parameters like affect, imagery and values. In addition the author suggests that response to climate risk could be associated with various psychological and socio-cultural factors. According to the European Commission's report [1] individuals in Western Europe tend to consider technological risks of higher importance compared to socio-economic ones. Quite the opposite applies for people from Easter Europe. Palutikof et al. [18] imply that there is evidence of socio-economic sensitivity to climate variability. Also, their work proposes that even though there is an indication of high level awareness, as regards climate change impact, strong differences based on the location of the respondents are noted. This is also supported by Taylor et al. [11] who investigated public perception of climate risk in UK; they concluded that it is important to understand regional differences to have effective adaptation policies. De Jalo et al. [32] mention that significant parameters that influence perception to climate risk include gender, age, family and profession. The work of Yang et al. [34] implies that confidence in policy, age, education and income level are amongst the key factors that determine willingness to pay to mitigate carbon emissions.

Wolf et al. [20] investigated how vulnerable groups of people perceive risks from heat and concluded that behaviors and responses to risk seem to be influenced by the perceptions those at risk and those providing support. Bird et al. [22] suggest that individuals' response during a hazard, like 
a volcanic eruption, is dependent not only on the emergency plan but also on the previous acquired knowledge and perception of the hazard itself. Lowe et al. [24] investigated the impact of a climate change related film to public perception in the UK. They highlighted that many people made a commitment on climate change mitigation after the film even though their level of actual knowledge about what this means seem to be limited.

Public perception to climate risk could also be associated with peoples' willingness to act. Bord et al. [36] point out that based on their analysis a limited willingness to sacrifice to better deal with climate change impact is noted. Even though people are willing to support climate change mitigation efforts they do not seem willing to alter their current lifestyle. In addition, Tobler et al. [21] investigated people's willingness to act in Switzerland and concluded that the perceived climate benefit and cost and political beliefs play an important role.

Amongst the limited research found on public perception on environmental issues of Greek citizens is the one implemented by Tsitsoni and Toma [13]; they analysed British and Greek people perception on environmental protection and climate change mitigation using Eurobarometer data and logistic regression. Their work identifies that people's opinion in both countries is influenced by common factors such as age, gender, occupation, purchasing power and environmental attitudes and perceptions. In the case of Greek citizens it is worth mentioning that education seems to be a really important parameter. Papoulis et al. [9] studied the opinion of Greek population residing in Athens area as regards climate change awareness and willingness to take actions. They conclude that the climate change awareness and actions towards adaptation seem to be influenced by the economic crisis Greece in currently facing.

The relationship between socio-demographic characteristics and environmental behavior is also pointed out by other researchers [11,18,20,32,34]. Considering the previous researches' results and scientific data reviewed, even though Greece is characterized as a vulnerable region in terms of climate related hazards, peoples' views and way of living do not always support this [13]. The key issue of this research is to investigate and analyse public perception in Greece as regards to climate change risk. In this context, by using a questionnaire survey this paper tries to analyse the way people feel about climate risk, their motivations to change current way of living and to undertake actions to adapt to a changing climate.

\section{Materials and Methods}

Public perception of climate risk in Greece was analysed by conducting a questionnaire survey. A structured questionnaire was developed, asking people to rate the significance of different issues associated with climate change based on their opinion. The questionnaire is structured by simple questions so that it can be easily understood by poor educated or elderly people. The questions included are of a more qualitative nature. Some questions are binary, while others may take certain values. In addition, there are questions that the answer comes in multiple certain answers, or the individual is asked to rank certain aspects described in the question.

The questionnaire was mostly distributed on-line from December 2014 until February 2015; however face-to-face interviews also took place. In total, the responses of 340 people were taken into consideration. The questionnaire includes five main parts. The first part includes some general questions regarding the importance people give to environmental problems. In the second part respondents are asked to rate the level of importance of climate risk in the case of Greece and to point out the most significant mitigation and adaptation measures. In addition, they are asked to highlight who is responsible to deal with the climate related risk. The third part of the questionnaire includes questions regarding individual actions undertaken or planned to mitigate or to adapt to climate change. This part is generally focused on individuals' willingness to take measures and aims at measuring individuals' attitude towards various aspects of perceived climate risk. The next part records the level of knowledge and source of information that people often use. Finally the last part asks for some socio-demographic data, like gender, age, level of education and geographical area.

Statistical analysis was carried out using simple spreadsheet program, as well as statistics/data analysis software (Stata 12, StataCorp). The analysis of the responses is used to draw some 
conclusions and to assess various parameters that are linked to climate risk perception. Our main purpose is to study the correlations between the answers the individuals gave, as well as to identify certain patterns of responding, according to individual characteristics. As our data do not have any continuous variables, we cannot rely solely on simple regression techniques that require the dependent variable to be continuous. We rather choose to employ the methodology of logistic regression, where the dependent variable is binary. With this method we are able to examine whether changes in some independent variables are associated with changes in the probability of choosing one option of the dependent variable over the other [36]. Similarly, we also follow the multinomial logistic regression methodology, where the dependent variable of interest may take different values, but is not continuous. In this case the aim is to test for any significant associations between a number of independent variables and their association with the probabilities of each individual option of answers. In our case, the dependent variables could be the answers of any questions that their probabilities might be significantly associated with any other set of questions. The significance of the estimated coefficients, will give us information on the sign and the size of the association, revealing important interrelations and dependences on the answers the individuals give to questions [36-38].

Another technique we employ is cluster analysis to cluster the data in different groups, according to a certain measure of distance; in our case we follow the k-means clustering with the Euclidean measure of distance. Clustering individuals according to certain responses they gave in various questions, we are able to examine the groups they can be formed and examine the special characteristics of these groups [39]. To be more precise, we group individuals according to the answers they gave in specific questions and then study the characteristics of these formed groups and their responses to other questions of the study. Another reason we employ clustering technics, is to create certain groups of individuals regarding their attitude towards climate risk and use this new variable as an independent in our logistic models described above.

Aiming at a more qualitative approach that includes certain parameters and characteristics we combined certain questions of the questionnaire to develop six indexes. The results of the indexes provide information on peoples' environmental awareness, their perception on climate risk, the willingness to adapt and to pay to minimise risk, as well as the existing level of knowledge and information acquired regarding climate risk. For all developed indexes a scale 0 to 5 is used.

Analytically, the following indexes are developed:

1) Environmental awareness: this index measures the level of awareness based on the importance people give to various environmental topics (climate change, air, water and soil pollution, ozone, biodiversity loss etc.) and responses regarding the importance of mitigation and adaptation measures. It includes responses on the following:

- Level of importance for environmental topics

- Level of importance for mitigation measures

- Level of importance for adaptation measures

2) Climate risk perception: This index measures the perceived level of importance of climate risk from different points of view. This index includes responses on the following:

- Level of importance for climate risk as an environmental topic

- Level of importance for climate risk for Greece

- Climate risk as a cause for altering current lifestyle

- Climate risk as a driver for action

3) Willingness to adapt: This index looks into people's willingness to adapt and their degree of concern. It takes into account responses on the following topics:

- Willingness to take measures

- Willingness to react to changes

- Willingness to alter environmental footprint

- Motivation for future choices 
4) Willingness to pay: This index looks into people's willingness to pay to deal with climate change impacts and it is based on responses associated with the following:

- Willingness to pay to minimise vulnerability (e.g. through taxation)

- Willingness to pay to secure assets (e.g. insurance)

- Opinion regarding compensation for post-disaster actions

5) Level of knowledge: This index looks into respondents' knowledge level on climate change related issues and takes into consideration their perception on the level of knowledge on the following:

- Level of knowledge for climate change impacts

- $\quad$ Level of knowledge for mitigation measures

- Level of knowledge for adaptation measures

6) Level of information: This index looks into respondents' level of information they have acquired on climate change and takes into account responses about the following:

- Level of information for climate change

- Level of information for climate related hazards (floods, draughts, heat events etc.)

- $\quad$ Level of information for climate risk for Greece

\section{Results}

\subsection{Sample characteristics}

Efforts were made to ensure that the distribution of some parameters, like age, sex and education are representative of the Greek population, taking into account information from the Hellenic Statistical Authority [40]. However, this was not possible for all the parameters.

The sample was structured so that it includes 51\% men and $49 \%$ women, representing the national sample with at least secondary education. Basic information about age, education and location of the respondents is given below:

The average age of the respondents ranges between $20-45$ years (68\%, SD 0.71$) .19 \%$ of the sample has age between $45-60$ years old and the rest (13\%) is either below 20 years old or above 60 years old.

The average level of education is having a post-graduate degree (38\%, SD 1.73). $25 \%$ of the sample possess a BSc degree, $15 \%$ a college or technical training degree and $22 \%$ have graduated from lyceum or gymnasium.

As regards the location of the respondents, $48 \%$ of the sample is located in Athens (SD 1.06) and $52 \%$ in the rest of Greece.

\subsection{Analysis results}

Amongst the problems Greece is currently facing, the economic situation (28\%) seems to overshadow climate change in the minds of people who consider it to be the second most serious problem $(24 \%)$. This choice seems to be associated with age and education as older and less educated people tend to consider economic crisis or immigration as the most important problem. Amongst other parameters it is worth mentioning that the higher education one has the higher the probability of choosing climate change over energy or water availability is. In the question how serious people consider climate change as a problem for Greece, 34\% consider it to be a very important problem, $59 \%$ a relatively important problem while $8 \%$ do not consider it a problem at all.

In the minds of people climate change impact seems to be related to temperature rise, extreme weather events, sea level rise, floods and draughts. Based on their views, green energy use, waste recycling, energy conservation, sustainable mobility and the use of recyclable materials seem to be important to climate change mitigation. As regards climate change adaptation people consider important the development of an action plan at national scale, culture change, efficient use of water, carrying out of water recycling initiatives and the implementation of measures at local scale. 
In the question whether people have taken some sort of action to fight climate change during the past 5 years $77 \%$ of the respondents gave a positive answer. Actions undertaken include waste recycling, increase in residential energy efficiency, energy and water conservation, the use of high energy efficiency appliances and the use sustainable forms of transport.

Clustering people based on their response on questions regarding climate change significance and actions undertaken or planned aiming at mitigating impact gave two distinctive profiles, $\mathrm{A}$ and B. Based on the analysis results moving from profile A to profile B changes the level of climate change significance and the willingness to change habits and to adapt. People that belong to profile A seem to present a more eco-friendly attitude, are more willing to adapt to new climatic conditions and are more willing to pay to mitigate impact. In addition, they consider culture change necessary towards climate change adaptation. Gender, age, education and location seem to be important factors (statistically significant), associated with the probability of belonging to profile A or B. Women are more likely to belong to profile A compared to men; this could imply that either women are more sensitive to environmental issues or men perceive risks as much smaller and more acceptable than women, which is consistent with the work of other researchers [41,42]. As regards age and education, it seems that older or less educated people are more likely to belong to profile $B$. The distance from Athens seems to be another important parameter associated with the probability of belonging to profile $\mathrm{B}$.

We assessed the level of information against the perceived level of significance that respondents give to climate risk to investigate whether there is a relationship. Based on the results, $44 \%$ of the sample that consider climate risk to be a significant issue possess above the average information on climate change.

Based on the analysis of the indexes' results (Table 1) risk perception and willingness to pay appear to get the higher average scores. Even though climate change is considered important as an environmental topic the level of importance as a problem for Greece seems to be low. It is worth mentioning that there seems to be a low degree of concern for adaptation measures, even though people's opinion on the economic benefits that those measures could result in for Greece is strong. In addition, there seems to be a strong willingness to pay for private insurance to deal with climate change effects; however people are not willing to pay (directly or indirectly through taxation) for the damages caused by extreme weather events.

Amongst the environmental topics there seems to be increased concern on water pollution and forest degradation and limited on soil erosion and acid rain. Amongst actions towards adaptation, people seem willing to implement those related to energy efficiency.

Table 1. Public perception indexes results

\begin{tabular}{lcc}
\hline \multicolumn{1}{c}{ Indexes } & Mean & SD \\
\hline Environmental awareness & 4.20 & 1.02 \\
Risk perception & 3.75 & 1.06 \\
Willingness to adapt & 3.48 & 0.96 \\
Willingness to pay & 3.69 & 1.07 \\
Level of knowledge & 2.27 & 1.27 \\
Level of information & 3.18 & 1.03 \\
\hline
\end{tabular}

Comparing the level of knowledge between climate change mitigation and adaptation measures it seems that in the first case the level of knowledge is higher. There seems to be a high level of information as regards climate change and the impact on temperature rise; however low level of information is noted regarding Greece's commitments to tackle climate change. This analysis also included an investigation of the similarities and differences between gender, age, education and location. From the gender perspective, men seem to have a higher level of information compared to women. As regards education, lower educated people seem more willing to pay compared to higher 
educated ones. Quite the same applies for elderly people. In the case of location all indexes get higher scores for Athens. In addition a T-test was conducted to compare the means of the population and to investigate whether the means of two groups are statistically different from each other. Based on the results we conclude that the scores assigned for the level of knowledge index seem to be due to the gender, age, education and location and not random. As regards level of information the scores assigned seem to be due to age, education and location and not random. Finally, with reference to environmental awareness, the scores assigned seem to be due to location and not random.

\section{Discussion}

Public perception and attitude do not always address climate change as the most important amongst other environmental issues or compared to socio-economic problems that Greece is currently facing. This seems to be consistent with the results from other research work $[11,18]$ that associates public perception with socio-economic conditions.

Greek peoples' attitudes in most of the cases seem to be influenced by a series of factors, like willingness to change habits and lifestyle, willingness to act \& willingness to pay. In addition, some of these factors could be further associated with demographic characteristics like gender, age or education.

People with lower education tend to be insecure about the impacts that climate change could have to their lives. Their perception in many cases is based on the information they have acquired from mass media and not on reliable scientific information. Also, based on the fact that the level of education could be associated with critical thinking maybe this anxiety about the climate threat could be due to the difficulty they face to see things clearly and make the right decisions. This in many cases is reported by increased willingness to pay for insurance coverage. It is worth mentioning that the same people tend to believe that the Greek Authorities are responsible for securing their private property against extreme weather events and for making them feel safe and secure.

Personal decisions associated with implementing mitigation or adaptation measures in many cases seem to be associated with financial issues. Even though information regarding the level of income has not been acquired, based on the responses it can be concluded that the choices people make to safeguard their property, to minimise energy footprint or to invest in more eco-friendly products or services tend to be influenced by the economic crisis Greece is currently facing.

\section{Conclusions}

This paper regards Greek peoples' perception on climate risk and analyses their opinion, behaviour, knowledge and readiness to change their habits, as well their willingness to pay in order to minimise risk. Based on the analysis the research presents the vulnerability of the Greek society to climate risk and highlights the factors that have shaped their beliefs. The results of this research could support the understanding of public views as regards to climate risk and for making possible the communication between communities, policy makers and scientists that could result in efficient adaptation planning.

\section{References}

1. European Commission. Climate Change, Special Eurobarometer 409, Wave EB80.2 - TNS Opinion \& Social. European Commission Report, 2014. Available online: http://ec.europa.eu/public_opinion/archives/ ebs/ebs_409_en.pdf (accessed on 1003 2016)

2. World Economic Forum. Global Risks 2015, 10th Edition, World Economic Forum Publication, 8-9; 53-55, 2015. Available online: http://www3.weforum.org/docs/WEF_Global_Risks_2015_Report15.pdf (accessed on 1003 2016)

3. Intergovernmental Panel on Climate Change (IPCC). Climate Change 2014 Synthesis Report, Summary for Policymakers, 2-32, 2014. Available online: http://www.ipcc.ch/report/ar5/syr/ (accessed on 1003 2016) 
4. European Environmental Agency. Climate change, impacts and vulnerability in Europe 2012, EEA Report No 12/2012. Available online: http://www.heritagecouncil.ie/fileadmin/user_upload/Publications/Marine/ Climate_change_-_impacts_and_vulnerability_in_Europe_2012_Summary.pdf (accessed on 1003 2016)

5. Commission of the European Communities. White Paper Adapting to climate change: Towards a European framework for action, 2-16, 2009. Available online: http://ec.europa.eu/health/ph_threats/ climate/docs/com_2009_147_en.pdf (accessed on 1003 2016)

6. European Parliament. Climate Change and Natural Disasters: Scientific evidence of a possible relation between recent natural disasters and climate change, Policy Department Economic and Scientific Policy, Briefing Note, IP/A/ENVI/FWC/2005-35, PE 373.583, 2006. Available online: http://www.europarl.europa.eu/ RegData/etudes/note/join/2006/373583/IPOL-ENVI_NT(2006)373583_EN.pdf (accessed on 1003 2016)

7. ESPON. Territorial Dynamics in Europe Natural Hazards and Climate Change in European Regions, Territorial Observation No. 7, 2013. Available online: https://www.espon.eu/export/sites/default/ Documents/Publications/TerritorialObservations/TO7_June2013/20130704_ESPON_TERRITORAL_07_CS 6_CM_Final.pdf (accessed on 1003 2016)

8. Bank of Greece. The Environmental, Economic and Social Impacts of Climate Change in Greece. Climate Change Impacts Study Committee Report, Economic Research Department, 2011. Available online: http://www.bankofgreece.gr/BoGEkdoseis/ClimateChange_FullReport_bm.pdf (accessed on 1003 2016)

9. Papoulis D.; Kaika D.; Bampatsou C.; Zervas E. Public Perception of Climate Change in a Period of Economic Crisis. Climate 2015, 3, 715-726, doi:10.3390/cli3030715

10. Koerth J.; Jones N.; Vafeidis A.T.; Dimitrakopoulos P.G.; Melliou A.; Chatzidimitriou E.; Koukoulas S. Household adaptation and intention to adapt to coastal flooding in the Axios - Loudias - Aliakmonas National Park, Greece. Ocean \& Coastal Management 2013, 82, 43-50, doi: doi.org/10.1016/j.ocecoaman.2013.05.008

11. Taylor A.L.; Dessai S.; Bruin W.B. Public perception of climate risk and adaptation in the UK: A review of the literature. Climate Risk Management 2014, 4-5, 1-16, doi:10.1016/j.crm.2014.09.001

12. Leiserowitz A. Climate Change risk perception and policy preferences: the role of affect, imagery and values. Climatic Change 2006, 77: 45-72, doi: 10.1007/s10584-006-9059-9

13. Tsitsoni V.; Toma L. An econometric analysis of determinants of climate change attitudes and behaviour in Greece and Great Britain. Agricultural Economics Review 2013, 14, 59-75

14. O'Brien et al. Toward a sustainable and resilient future. In: Managing the Risks of Extreme Events and Disasters to Advance Climate Change Adaptation, A Special Report of Working Groups I and II of the Intergovernmental Panel on Climate Change (IPCC), Cambridge University Press, Cambridge, UK, and New York, NY, USA, 2012, 437-486

15. Cutter S.L.; Schumann III R.L.; Emrich C.T. Exposure, Social Vulnerability and Recovery Disparities in New Jersey after Hurricane Sandy. J. of Extr. Even. 2014, 01, 1450002, doi: 10.1142/S234573761450002X

16. Yuab et al. A vulnerability index for post-disaster key sector prioritization. Economic Systems Research, Special Issue: Disaster Impact and Input-Output Analysis 2014, 26 (1), 81-97, http://hdl.handle.net/10.1080/09535314.2013.872603

17. Sietz D. Regionalisation of global insights into dryland vulnerability: Better reflecting smallholders' vulnerability in Northeast Brazil. Global Environmental Change 2014, 25, 173-185

18. Palutikof J.P., Agnew M.D., Hoar M.R. Public perceptions of unusually warm weather in the UK: impacts, responses and adaptations. Clim Res 2004, 26, 43-59

19. Bellamy R.; Hulme M. Beyond the Tipping Point: Understanding Perceptions of Abrupt Climate Change and Their Implications. Weather, Climate, and Society 2011, 3, 48-60, doi: 10.1175/2011WCAS1081.1

20. Wolf J.; Adger W.N.; Lorenzoni I.; Abrahamson V.; Raine R. Social capital, individual responses to heat waves and climate change adaptation: An empirical study of two UK cities. Global Environmental Change 2010, 20, 44-52, doi:10.1016/j.gloenvcha.2009.09.004

21. Tobler et al. Addressing climate change: Determinants of consumers' willingness to act and to support policy measures. Journal of Environmental Psychology 2012, 32:197-207, doi: 10.1016/j.jenvp.2012.02.001

22. Bird D.K.; Gisladottir G.; Dominey-Howes D. Resident perception of volcanic hazards and evacuation procedures. Nat. Hazards Earth Syst. Sci. 2009, 9, 251-266, doi:10.5194/nhess-9-251-2009

23. Harries T. The anticipated emotional consequences of adaptive behavior - impacts on the take-up of household flood-protection protective measures. Environment and Planning A 2012, 44(3), 649-668, doi: $10.1068 / \mathrm{a} 43612$ 
24. Lowe T.; Brown K.; Dessai S.; Doria MF.; Haynes K.; Vincent K. Does tomorrow ever come? Disaster narrative and public perceptions of climate change. Public Understand. Sci. 2006, 15, 435-457, doi: 10.1177/0963662506063796

25. Buchecker M.; Salvini G.; Di Baldassarre G.; Semenzin E.; Maidl E.; Marcomini A. The role of risk perception in making flood risk management more effective. Nat. Hazards Earth Syst. Sci. 2013, 13, 30133030, doi:10.5194/nhess-13-3013-2013

26. Bradford R.A.; O'Sullivan J.KJ.; Van der Craats I.M.; Krywkow J.; Rotko P.; Aaltonen J.; Bonaiuto M.; De Dominicis S.; Waylen K.; Schelfaut K. Risk perception - issues for flood management in Europe. Nat. Hazards Earth Syst. Sci. 2012, 12, 2299-2309, doi:10.5194/nhess-12-2299-2012

27. Slovic P.; Fischhoff B.; Lichtenstein S. Why study risk perception? Risk Analysis 1982, 2 (2), doi: 10.1111/j.1539-6924.1982.tb01369.x

28. Raaijmakers, R.; Krywkow, J.; Veen, A. Flood risk perceptions and spatial multi-criteria analysis: an exploratory research for hazard mitigation. Natural Hazards 2008, 46 (3), 307-322

29. European Commission (2014), Public risk perception and environmental policy, Science for Environment Policy, Future Brief, Policy Report Issue 8. Available online: http://ec.europa.eu/environment/integration/ research/newsalert/pdf/public_risk_perception_environmental_policy_FB8_en.pdf (accessed on 1003 2016)

30. Wei J.; Hansen A.; Zhang Y.; Li H.; Liu Q.; Sun Y.; Bi P. Perception, attitude and behavior in relation to climate change: A survey among CDC health professionals in Shanxi province, China. Environmental Research 2014, 134, 301-308, doi: 10.1016/j.envres.2014.08.006

31. Wolf J. Climate Change Adaptation in Developed Nations: From Theory to Practice, In: Advances in Global Change Research, J.D. Ford and L. Berrang-Ford, Eds., 42, 2011, doi: 10.1007/978-94-007-0567-8 2

32. De Jalo S.G.; Iglesias A.; Quiroga S.; Bardaj I. Exploring public support for climate change adaptation policies in the Mediterranean region: A case study in Southern Spain. Environmental Science E Policy 2013, 29, 1-11, doi:10.1016/j.envsci.2013.01.010

33. Niles M.T.; Lubell M.; Hadem V.R. Perceptions and responses to climate policy risks among California farmers. Global Environmental Change 2013, 23, 1752-1760, http://dx.doi.org/10.1016/j.gloenvcha.2013.08.005

34. Yang J.; Zou L.; Lin T.; Wu Y.; Wang H. Public willingness to pay for CO2 mitigation and the determinants under climate change: A case study of Suzhou, China. Journal of Environmental Management 2014, 146, 1-8, doi: 10.1016/j.jenvman.2014.07.015

35. Bord R.J.; Fisher A.; O'Connor R.E. Public perceptions of global warming: United States and international perspectives. Climate Research 1998, 11, 75-84

36. Cramer, J. S. Logit Models from Economics and Other Fields, Cambridge University Press, Cambridge, 2003

37. Greene, W. H. Econometric Analysis, 7th ed.; NJ: Prentice Hall Upper Saddle River, 2012

38. Rencher, A. C. Methods of Multivariate Analysis, 2nd ed.; Wiley New York, 2002

39. Everitt, B. S. Cluster Analysis, 3rd ed.; Arnold London, 1993

40. Hellenic Statistical Authority. Demographic and social characteristics of the Resident Population of Greece according to the 2011 Population - Housing Census revision of 20/3/2014. Hellenic Statistical Authority Report 2014. Available online: http://www.statistics.gr/en/2011-census-pop-hous (accessed on 1003 2016)

41. Bickerstaff K. Risk perception research: socio-cultural perspectives on the public experience of air pollution. Environ Int. 2004, 30 (6), 827-40, doi:10.1016/j.envint.2003.12.001

42. Bier, V. On the state of the art: risk communication to the public. Reliability Engineering $\mathcal{E}$ System Safety 2001, 71 (2), 139-150, doi: 10.1016/S0951-8320(00)00090-9

(C) 2016 by the authors; licensee Preprints, Basel, Switzerland. This article is an open access article distributed under the terms and conditions of the Creative Commons by Attribution (CC-BY) license (http://creativecommons.org/licenses/by/4.0/). 